\title{
THE TACTICS FEATURES FOR THE COMMISSION OF JUDICIAL ECONOMIC EXAMINATIONS IN INVESTIGATING CRIMES RELATED TO FINANCIAL AND ECONOMIC ACTIVITIES OF THE SUBJECTS OF HOUSING AND COMMUNAL SERVICES
}

\author{
Svyatoslav Yu. Biryukov \\ Volgograd Academy of the Ministry of Interior of Russia,Volgograd, Russian Federation \\ Vladimir M. Shynkaruk \\ Volgograd State University, Volgograd, Russian Federation
}

\begin{abstract}
Introduction: crimes in the sphere of housing and communal services pose a serious social danger and are of acute social nature, as they affect the interests of the state and society. Crimes in this economy sector lead to the violations of the legal property rights of tens of thousands of citizens, their social and economic security. The facts of criminal activity in the sphere of housing and communal services, the insufficiently rapid response of the law enforcement agencies to them, delay or protraction in the investigation of these facts, form the prerequisites and contribute to the protest activity of the population which destabilizes the socio-political situation.

In this regard, the effective counteraction of the considered category of illegal acts requires prompt and full investigation of all facts of the criminal activity committed in the sphere of housing and communal services in order to ensure the inevitability of punishment for committing them and compensation for the material damage. The investigation of crimes of the specified category, as a rule, is impossible without carrying out various judicial economic examinations whose commission, performance and conclusions assessment in many respects predetermine the prospects for successful resolution of the criminal case in court.

In this regard, the authors set a goal to reveal the tactical features of the commission of such an important for the investigation of most crimes committed in the field of housing and communal services, investigative action as a judicial economic examination. Methods: the methodological framework for this study is a set of methods of scientific knowledge, among which the main are the methods of information processing and logical analysis, synthesis, induction, deduction and generalization. Results: the author's content of the tactical features of commissioning a judicial economic examination on the facts of crimes connected with financial and economic activities of the subjects of housing and communal services based on the judicial and investigative practice gives the chance to use them in the practical activities of the authorized officials of the law enforcement agencies during the identification and investigation of the $\infty$ above-mentioned facts. Conclusions: as a result of the study, the authors have determined the tactical features of the commission of a judicial economic examination on the facts of crimes related to financial and economic activities of the subjects of housing and communal services in order to inform law students, the teaching staff of law schools, as well as practitioners in order to better understand the features of the investigation of crimes, connected with the financial and economic activities of the subjects of housing and communal services. 当 expert.

Key words: housing and communal services, financial and economic activity, forensic examination,

Citation. Biryukov S.Yu., Shynkaruk V.M. The Tactics Features for the Commission of Judicial Economic Examinations in Investigating Crimes Related to Financial and Economic Activities of the Subjects of Housing and Communal Services. Legal Concept, 2018, vol. 17, no. 3, pp. 133-140. DOI: https://doi.org/10.15688/ 1c.jvolsu.2018.4.19
\end{abstract}




\title{
ОСОБЕННОСТИ ТАКТИКИ НАЗНАЧЕНИЯ СУДЕБНЫХ ЭКОНОМИЧЕСКИХ ЭКСПЕРТИЗ В ХОДЕ РАССЛЕДОВАНИЯ ПРЕСТУПЛЕНИЙ, СВЯЗАННЫХ С ФИНАНСОВО-ХОЗЯЙСТВЕННОЙ ДЕЯТЕЛЬНОСТЬЮ СУБЪЕКТОВ ЖИЛИЩНО-КОММУНАЛЬНОГО ХОЗЯЙСТВА
}

\author{
Святослав Юрьевич Бирюков \\ Волгоградская академия МВД России, г. Волгоград, Российская Федерация \\ Владимир Маркович Шинкарук \\ Волгоградский государственный университет, г. Волгоград, Российская Федерация
}

\begin{abstract}
Введение: преступления в сфере жилищно-коммунального хозяйства представляют серьезную общественную опасность и носят остросоциальный характер, поскольку затрагивают интересы государства и общества. Преступления в данной отрасли экономики приводят к нарушениям законных имущественных прав десятков тысяч граждан, их социально-экономической защищенности. Факты преступной деятельности в сфере жилищно-коммунального хозяйства, недостаточно оперативное реагирование на них правоохранительных органов, промедление либо затягивание расследования указанных фактов - все это формирует предпосылки и способствует протестной активности населения, что дестабилизирует общественнополитическую ситуацию.

В этой связи эффективное противодействие рассматриваемой категории противоправных деяний требует оперативного и полноценного расследования всех фактов преступной деятельности, совершаемых в сфере жилищно-коммунального хозяйства, в целях обеспечения неотвратимости наказания за их совершение и возмещения материального ущерба. Расследование же преступлений указанной категории, как правило, невозможно без проведения различных судебных экономических экспертиз, назначение, производство и оценка заключений которых во многом предопределяют перспективы успешного разрешения уголовного дела в суде.
\end{abstract}

В связи с этим авторами поставлена цель раскрыть тактические особенности назначения такого важного для расследования большинства преступлений, совершаемых в сфере жилищно-коммунального хозяйства, следственного действия, как судебная экономическая экспертиза. Методы: методологическую основу данного исследования составляет совокупность методов научного познания, среди которых основное место занимают методы обработки информации и логического анализа, синтеза, индукции, дедукции и обобщения. Результаты: представленное в работе авторское содержание тактических особенностей назначения судебной экономической экспертизы по фактам преступлений, связанных с финансово-хозяйственной деятельностью субъектов жилищно-коммунального хозяйства, опирающееся на судебно-следственную практику, дает возможность использовать их в практической деятельности уполномоченных должностных лиц правоохранительных органов в ходе выявления и расследования вышеназванных фактов. Выводы: в результате исследования определены тактические особенности назначения судебной экономической экспертизы по фактам преступлений, связанных с финансово-хозяйственной деятельностью субъектов жилищно-коммунального хозяйства, в целях информирования обучающихся по направлению подготовки «Юриспруденция», педагогических работников юридических вузов, а также практических работников в целях более полного понимания их особенностей.

Ключевые слова: жилищно-коммунальное хозяйство, финансово-хозяйственная деятельность, судебная экспертиза, эксперт.

Цитирование. Бирюков С. Ю., Шинкарук В. М. Особенности тактики назначения судебных экономических экспертиз в ходе расследования преступлений, связанных с финансово-хозяйственной деятельностью субъектов жилищно-коммунального хозяйства // Legal Concept = Правовая парадигма. - 2018. - T. 17, № 4. C. 133-140. - DOI: https://doi.org/10.15688/lc.jvolsu.2018.4.19 


\section{Значение использования}

специальных знаний в ходе

расследования преступлений

в жилищно-коммунальной сфере

Практика использования специальных знаний сведущих лиц в ходе расследования преступлений, связанных с финансово-хозяйственной деятельностью субъектов жилищно-коммунального хозяйства, свидетельствует о имеющихся проблемах при назначении, производстве судебных экономических экспертиз, последующей оценке заключения эксперта, а также взаимодействия лица, осуществляющего расследование с экспертами.

Рассматриваемая категория уголовных дел, как правило, возбуждается по признакам преступлений, предусмотренных следующими статьями Уголовного кодекса Российской Федерации: 159 «Мошенничество», 160 «Присвоение или растрата», 165 «Причинение имущественного ущерба путем обмана или злоупотребления доверием», 171 «Незаконное предпринимательство», 174 «Легализация (отмывание) денежных средств или иного имущества, приобретенных другими лицами преступным путем», 174.1 «Легализация (отмывание) денежных средств или иного имущества, приобретенных лицом в результате совершения им преступления», 201 «Злоупотребление полномочиями», 285 «Злоупотребление должностными полномочиями», 285.1 «Нецелевое расходование бюджетных средств» и др.

Сейчас очевидно, что эффективность раскрытия и расследования уголовных дел во многом зависит от использования в уголовном процессе естественнонаучных, экономических и других специальных познаний. Закон не дает определения понятия «специальные знания». Под этим термином обычно понимают знания, приобретенные при получении специального образования или в процессе практической работы по конкретной специальности [3, с. 20]. Не относятся к специальным общеизвестные, а также юридические познания [9, с. 181].

Формы использования специальных познаний могут быть различны. Предусмотрена возможность привлечения специалиста к производству следственных и судебных действий, где он использует свои специальные знания и навыки для содействия следовате- лю в обнаружении, закреплении и изъятии доказательств; обращает его внимание на обстоятельства, связанные с обнаружением и закреплением доказательств; дает пояснения по поводу специальных вопросов, возникающих при производстве следственных действий [2, с. 66]. Сведения о фактах, установленных специалистом путем непосредственного наблюдения, фиксируются в протоколе следственного действия [8, с. 194].

Другой и, как представляется, главной процессуальной формой использования специальных знаний является судебная экспертиза. Сущность судебной экспертизы состоит в анализе по заданию следователя сведущим лицом - экспертом - предоставляемых в его распоряжение материальных объектов экспертизы (вещественных доказательств), а также различных документов (в том числе протоколов следственных действий) с целью установления фактических данных, имеющих значение для правильного разрешения дела. По результатам исследования эксперт составляет заключение, которое является одним из предусмотренных законом источников доказательств, а фактические данные, содержащиеся в нем, - доказательствами [6, с. 39].

\section{Предмет и цели назначения экономических экспертиз}

Предмет судебной экспертизы составляют фактические данные, устанавливаемые в ходе предварительного расследования по уголовному делу $[1$, с. $91 ; 5]$.

Основными целями назначения экономических экспертиз по уголовным делам о преступлениях, связанных с финансово-хозяйственной деятельностью субъектов жилищно-коммунального хозяйства, являются:

1. Установление полноты исполнения потребителями услуг, обслуживающими (агентами) и ресурсоснабжающими организациями - договорных обязательств по предоставлению и оплате жилищных и коммунальных услуг.

2. Установление сумм и направлений расходования обслуживающими организациями (агентами) денежных средств.

3. Установление суммы дохода, полученного обслуживающими и ресурсоснабжающи- 
ми организациями от осуществления деятельности по оказанию (предоставлению) жилищных и коммунальных услуг.

4. Установление правильности (корректности) тарификации (перерасчет, корректировка, необоснованное предъявление).

5. Установление стоимости обслуживания (ремонт, капитальный ремонт, модернизация) объектов жилищно-коммунального хозяйства (коммунальных сетей, зданий, помещений).

6. Установление сумм и направлений расходования ресурсоснабжающими организациями денежных средств, материальных ценностей.

\section{Сроки проведения экономических экспертиз}

Актуальной проблемой расследования уголовных дел рассматриваемой категории продолжает оставаться длительность, обусловленная необходимостью производства сложных и дорогостоящих судебных экспертиз, предметом исследований которых является финансово-хозяйственная деятельность компаний, связанных с деятельностью субъектов жилищно-коммунального хозяйства, без производства которых невозможно установить все обстоятельства, подлежащие доказыванию в соответствии со ст. 73 УПК Российской Федерации, и соответственно завершить предварительное следствие.

Большая очередность в государственных экспертных учреждениях и длительность проведения экспертиз не позволяют органам предварительного следствия принимать законные решения в разумные сроки [7].

Так, по находящемуся в производстве СУ УМВД России по г. Омску уголовному делу, возбужденному по признакам преступления, предусмотренного ч. 3 ст. 159 УК РФ, 14.09.2017 назначена дополнительная судебная экономическая экспертиза, при этом срок начала ее производства определен не ранее марта 2018 года [4].

Подобные факты носят распространенный характер и требуют от следователей ответственного подхода к назначению данного вида экспертиз, в том числе с целью исключения оснований для назначения дополнительных и повторных экспертиз.
Учитывая сложившуюся ситуацию при назначении данного вида судебных экспертиз и их объективную сложность, в целях сокращения сроков их производства следователю при принятии процессуального решения о назначении экспертизы необходимо:

1. Использовать результаты исследований, проведенных специалистами-ревизорами подразделений экономической безопасности и противодействия коррупции территориальных органов МВД России.

2. Привлекать сотрудников экспертнокриминалистических подразделений территориальных органов МВД России для проведения «доэкспертной» оценки материалов уголовного дела, а именно:

- для выявления особенностей финансово-хозяйственной деятельности исследуемого лица, требующих отражения в постановлении о назначении экспертизы, которые впоследствии будут использованы экспертом в качестве исходных данных;

- постановки корректной экспертной задачи;

- определения перечня необходимых объектов исследования.

\section{Квалификация преступлений в сфере жилищно-коммунального хозяйства}

Следует учитывать, что применяемая методика экспертного исследования финансово-хозяйственной деятельности субъектов жилищно-коммунального хозяйства зависит от проведенной следователем уголовно-правовой квалификации деяния, совершенного исследуемым лицом. Так, следователю необходимо в установочной части постановления о назначении экспертизы (либо сообщив дополнительно) подробно описать (отразить) механизм совершения преступления, а также наиболее значимые обстоятельства по уголовному делу, которые могут быть использованы экспертом в качестве исходных данных при выборе методов исследования, а также при определении перечня исследуемых объектов, а именно:

- правовой статус (организационно-правовую форму) исследуемого лица;

- порядок осуществления деятельности исследуемым лицом; 
- форму и порядок проведения расчетов (в том числе получения / списания денежных средств) за жилищные и коммунальные услуги;

- особенности учета (принципы, закономерности, правила, документооборот) оказанных (предоставленных) жилищных и коммунальных услуг в исследуемом периоде, в том числе если учет услуг велся посредством составления «черновых» записей;

- сведения о потребителях услуг, в отношении которых следует провести исследование, с указанием адресов объектов, по которым оказывались (предоставлялись) жилищные и коммунальные услуги обслуживающими организациями, и (или) пофамильные (поквартирные) списки нанимателей и собственников.

Указанные сведения необходимо учитывать следователю при постановке вопросов, ставящихся на разрешение эксперта, а эксперту следует отражать их в исследовательской части заключения.

Следует также учитывать, что ставящиеся на разрешение эксперта вопросы должны удовлетворять следующим требованиям:

1. Не выходить за пределы компетенции эксперта.

2. Предполагать необходимость проведения специальных исследований.

3. Быть четкими, ясными, не допускающими двоякого толкования, конкретизированными в отношении объектов, обстоятельств, лиц и времени.

\section{Задачи, ставящиеся на разрешение экономических экспертиз по уголовным делам \\ в жилищно-коммунальной сфере}

Таким образом, экспертные задачи, ставящиеся на разрешение эксперта, должны быть конкретизированы в отношении (или в части):

- наименований, ИНН и номеров счетов исследуемого лица;

- периода, за который требуется провести исследование (с указанием точных дат начала и окончания исследуемого периода либо отражения (в случае необходимости) отчетных дат и периодов (например, «по состоянию на первое число каждого месяца» и (или) «помесячно»);

- вида деятельности, осуществленной исследуемым лицом;
- потребителей услуг.

Не допускается постановка перед экспертом:

1. Справочных вопросов, то есть вопросов, не требующих проведения исследования с использованием экспертных методов.

2. Правовых вопросов, то есть вопросов, связанных с оценкой деяния, разрешение которых относится к исключительной компетенции следователя (определение ответственности и вины лиц, размера материального ущерба).

Например, такие вопросы, как: «Существуют ли признаки преднамеренного банкротства МУП “Городская управляющая компания"?», «Какую общую сумму денежных средств ООО «УК "Пересвет"» незаконно предъявило в счетах-фактурах по актам № 000111 от 30.05.2017 и № 000222 от 30.06.2017 за механизированную уборку территории по муниципальному контракту № 1234567 от 29.05.2017, заключенному с МКУ “Дирекция муниципального обслуживания”?», «Какова сумма незаконно начисленной и выплаченной премии следующим работникам ООО «УК “Пересвет”»: Иванова И.И., Петрова П.П., Сидорова С.С. за период с 01.01.2017 по 31.12.2017?», «Поступали ли обратно в кассу ООО «УК “Пересвет”» незаконно выплаченные премии Иванову И.И., Петрову П.П., Сидорову С.С. за период с 01.01.2014 по 31.05.2016»?

Данные вопросы предполагают проведениеэкспертом уголовно-правовой квалификации совершенного деяния, определение законности (незаконности) осуществленной хозяйственной операции, а также установление факта фиктивности (подлинности) представляемых документов, относятся к исключительной компетенции лица или органа, назначившего экспертизу.

3. Ревизионных вопросов, то есть вопросов, подразумевающих проведение сплошного исследования всей финансово-хозяйственной деятельности (ее объемных участков) исследуемого лица за определенный период, в том числе с постановкой задачи по выявлению отклонений и нарушений.

Например: «Имелась ли у ООО «УК “Пересвет"», исходя из материального положения в период с 01.01.2017 по 31.12.2017, реальная возможность производить выплаты по исполнительным листам?»; «Имело ли ООО «УК “Пересвет”» возможность погасить имеющуюся кредиторскую задолженность в 
2016 году? В 2017 году?». Такие вопросы не могут быть разрешены в рамках судебной экспертизы, поскольку наряду с оценкой финансово-хозяйственного состояния организации предполагают оценку всех экономических факторов, оказавших влияние на управленческие решения в исследуемом периоде. Формулировки данного типа вопросов следует заменить на вопросы, направленные на определение сумм денежных средств, которыми располагало исследуемое лицо в исследуемом периоде и (или) на конкретную дату, а также на установление целей расходования исследуемой организацией денежных средств в исследуемом периоде.

«Какими показателями характеризовалось финансово-экономическое состояние МУП “Городская управляющая компания" за период с 01.01.2017 по 31.12.2017?», «Какие финансовохозяйственные отношения имелись между МУП “Городская управляющая компания" и МУП “Дирекция по управлению коммунальным хозяйством” в период с 01.01.2017 по 31.12.2017?». Данные вопросы, предусматривают проведение сплошной проверки всего бухгалтерского учета или объемных его участков. Такие вопросы не могут быть разрешены в рамках судебной экспертизы, поскольку их формулировки не конкретизированы в отношении предмета исследования - не поставлена конкретная экспертная задача. Формулировки данного типа вопросов следует конкретизировать в отношении предмета и объекта исследования.

«Целесообразны ли были договорные отношения между МУП “Городская управляющая компания” и МУП “Дирекция по управлению коммунальным хозяйством” для финансово-экономического состояния МУП “Городская управляющая компания”?». Указанный вопрос связан с определением целесообразности (нецелесообразности) совершения тех или иных хозяйственных операций. Такого рода вопросы не могут быть разрешены в рамках судебной экспертизы, поскольку проведение исследования по ним выходит за пределы компетенции эксперта-бухгалтера. Формулировки данного типа вопросов следует корректировать с целью исключения необходимости дачи оценки экспертом тем или иным принятым управленческим решениям в рамках деятельности исследуемого лица.

\section{Объекты экономических экспертиз}

Объектами исследования бухгалтерских судебных экспертиз данного вида являются содержащиеся в материалах уголовного дела материальные носители сведений, относящихся к предмету экспертизы. Они могут быть представлены как на бумажных носителях, так и на неперезаписываемых дисках исключительно формата CD-R или DVD-R.

Объекты исследования на бумажных носителях необходимо представлять сшитыми в тома (без повреждения сведений, содержащихся в них), пронумерованными и опечатанными. К представляемым для производства экспертизы томам и (или) сшивам должна прилагаться соответствующая подробная опись документов, заверенная подписью следователя.

В случае представления объектов исследования на неперезаписываемых дисках формата CD-R или DVD-R следователю необходимо указывать:

- номер, нанесенный вокруг посадочного отверстия диска;

- сведения о невозможности внесения изменений в содержащиеся на дисках данные программными средствами;

- полное наименование содержащихся на диске файлов, их формат, пароли и (или) имена пользователей (при их наличии) для беспрепятственного доступа к данным, содержащимся в файлах;

- сведения о содержащихся в файлах данных;

- при наличии множества папок - путь к исследуемым файлам;

- при наличии нескольких файлов (папок), содержащих идентичные документы (однотипные данные), но имеющих расхождения в сведениях, отраженных в них, - информацию о файлах (папках), данные которых необходимо использовать в качестве исходных при производстве экспертизы.

Также при назначении судебных экономических экспертиз в ходе расследования преступлений, связанных с финансово-хозяйственной деятельностью субъектов жилищно-коммунального хозяйства, лицам, производящим расследование, необходимо учитывать следующие аспекты производства данных экспертных исследований: 
1. В случае отсутствия в объектах, представленных для проведения исследования, достоверной информации, принятие во внимание которой существенно меняет экономическое содержание отраженных обстоятельств финансово-хозяйственной деятельности, следователю необходимо указать ее в качестве исходных данных в постановлении о назначении экспертизы либо сообщить дополнительно.

2. В случае предоставления объектов исследования, содержащих сокращения наименований оказанных жилищных и коммунальных услуг, следователю необходимо указать расшифровки данных сокращений в качестве исходных данных в постановлении о назначении экспертизы либо сообщить дополнительно.

3. В случае предоставления объектов исследования, содержащих информацию об оказанных жилищных и коммунальных услугах, не соответствующих по наименованию услугам, в отношении которых поставлена экспертная задача, следователю необходимо разъяснить порядок отнесения указанных услуг к услугам, в отношении которых поставлена экспертная задача, в качестве исходных данных в постановлении о назначении экспертизы либо сообщить дополнительно. Например: «...Считать в квитанциях об оплате коммунальных услуг услугу “подогрев воды” как "горячее водоснабжение", а "канализирование" как “водоотведение"...».

4. В случае отсутствия в объектах, представленных для проведения исследования (первичных учетных документах и регистрах бухгалтерского учета), обязательных реквизитов эксперт не вправе самостоятельно принимать решение о недостоверности информации, содержащейся в объектах, и исключать их из числа исследуемых материалов. Принимая такое решение, эксперт превышает пределы своей компетенции, так как оценка материалов уголовного дела на относимость, допустимость и достоверность относится к исключительной компетенции следователя (ст. 87 и 88 Уголовно-процессуального кодекса Российской Федерации).

5. В случаях, когда вопрос эксперту заключается в определении искомого показателя за неполный месяц (начало / окончание периода исследования не совпадает с расчетным периодом (календарным началом / окончанием) месяца), а также при отсутствии объек- тов, позволяющих определить искомый показатель на исследуемую дату, следователю необходимо представить разъяснение по порядку его определения (в том числе посредством проведения допросов лиц, способных дать соответствующую информацию).

\section{СПИСОК ЛИТЕРАТУРЫ}

1. Бирюков, С. Ю. О некоторых проблемах профилактики преступлений в сфере предпринимательства / С. Ю. Бирюков, Ю. С. Стешенко // Вестник Волгоградской академии МВД России. - 2013. - Вып. 4 (27).

2. Бирюков, С. Ю. Оценка заключения судебной психиатрической экспертизы на стадии предварительного расследования / С. Ю. Бирюков // Вестник Волгоградской академии МВД России. - 2017. - Вып. 1 (40).

3. Коловоротный, А. А. Использование специальных психологических знаний при расследовании организации преступного сообщества / А. А. Коловоротный // Судебная экспертиза. 2012. - № 4 (32). - С. 19-32.

4. Материалы уголовного дела № 1170152 0056000144 // Архив Центрального районного суда г. Омска.

5. Пупцева, А. В. Особенности и порядок назначения судебных экспертиз при расследовании преступлений, связанных с незаконным оборотом наркотиков / А. В. Пупцева, Д. Г. Скориков // Современные проблемы науки и образования. - 2015. - № 1. Электрон. текстовые дан. - Режим доступа: www. science-education.ru/121-18512 (дата обращения: 10.09.2018). - Загл. с экрана.

6. Скориков, Д. Г. Особенности назначения судебных экспертиз при расследовании преступлений экстремистской направленности / Д. Г. Скориков // Судебная экспертиза : науч.-практ. журн. 2013. - Вып. 1 (33). - С. 39-46.

7. Соловьева, Н. А. Взаимосвязь процессуальной истины и разумных сроков ее установления / Н. А. Соловьева, В. М. Шинкарук // Вестник Волгоградского государственного университета. Серия 5, Юриспруденция. - 2014. - № 4. - С. 159-164.

8. Шувалов, Н. В. К вопросу использования экономических знаний по преступлениям в кредитно-банковской сфере / Н. В. Шувалов // Научный фундамент практической деятельности по расследованию преступлений : сб. ст. Междунар. науч.-практ. конф. (06.04.2017 г.) / редкол.: Н. В. Шувалов, Д. В. Кайргалиев, Ю. С. Сафонова. - Самара : Офорт, 2017.

9. Шувалов, Н. В. Об отдельных аспектах специальных знаний, используемых при расследовании незаконного получения кредита / Н. В. Шувалов // Актуальные вопросы современной юриди- 
ческой науки : сб. ст. Междунар. науч.-практ. конф. (17 февр. 2017 г.) / редкол.: С. Ю. Бирюков, Д. В. Кайргалиев. -Алматы : Изд-во LEM, 2017.

\section{REFERENCES}

1. Biryukov S.Yu., Steshenko Yu.S. O nekotorykh problemakh profilaktiki prestupleniy v sfere predprinimatelstva [On Some Problems of Crime Prevention in the Sphere of Entrepreneurship]. Vestnik Volgogradskoy akademii MVD Rossii, 2013, iss. 4 (27).

2. Biryukov S.Yu. Otsenka zaklyucheniya sudebnoy psikhiatricheskoy ekspertizy na stadii predvaritelnogo rassledovaniya [Evaluation of the Opinion of the Forensic Psychiatric Examination at the Stage of Preliminary Investigation]. Vestnik Volgogradskoy akademii MVD Rossii, 2017, iss. 1 (40).

3. Kolovorotnyy A.A. Ispolzovanie spetsialnykh psikhologicheskikh znaniy pri rassledovanii organizatsii prestupnogo soobshchestva [The Use of Special Psychological Knowledge in the Investigation of Criminal Community]. Sudebnaya ekspertiza, 2012, no. 4(32), pp. 19-32.

4. Materialy ugolovnogo dela № 117015200560 00144 [Materials of Criminal Case No. 117015200560 00144]. Arkhiv Tsentralnogo rayonnogo suda g. Omska [Archive of the Central District Court of Omsk].

5. Puptseva A.V., Skorikov D.G. Osobennosti i poryadok naznacheniya sudebnykh ekspertiz pri rassledovanii prestupleniy, svyazannykh s nezakonnym oborotom narkotikov [Features and the Procedure for the Appointment of Forensic Examinations in the Investigation of Crimes Related to Drug Trafficking]. Sovremennye problemy nauki $i$ obrazovaniya, 2015, no. 1. URL: www.scienceeducation.ru/121-18512 (accessed 10 September 2018).

6. Skorikov D.G. Osobennosti naznacheniya sudebnykh ekspertiz pri rassledovanii prestupleniy ekstremistskoy napravlennosti [Features of the Appointment of Forensic Examinations in the Investigation of Extremist Crimes]. Sudebnaya ekspertiza: nauch.-prakt. zhurn., 2013, iss. 1 (33), pp. 39-46.

7. Solovyeva N.A., Shinkaruk V.M. Vzaimosvyaz protsessualnoy istiny i razumnykh srokov ee ustanovleniya [Interrelation of Procedural Truth and Reasonable Terms of Its Establishment]. Vestnik Volgogradskogo gosudarstvennogo universiteta. Seriya 5, Yurisprudentsiya [Science Journal of Volgograd State University. Jurisprudence], 2014, no. 4, pp. 159-164.

8. Shuvalov N.V. K voprosu ispolzovaniya ekonomicheskikh znaniy po prestupleniyam v kreditnobankovskoy sfere [On the Use of Economic Knowledge on Crimes in the Credit and Banking Sector]. Shuvalov N.V., Kayrgaliev D.V., Safonova Yu.S., eds. Nauchnyy fundament prakticheskoy deyatelnosti po rassledovaniyu prestupleniy: sb. st. Mezhdunar. nauch.prakt. konf. (06.04.2017 g.) [Scientific Foundation of Practical Activities for Investigating Crimes: Collected Papers of International Research and Practice Conference (April 6, 2017)]. Samara, Ofort Publ., 2017.

9. Shuvalov N.V. Ob otdelnykh aspektakh spetsialnykh znaniy, ispolzuemykh pri rassledovanii nezakonnogo polucheniya kredita [On Certain Aspects of Special Knowledge Used in the Investigation of Unlawful Receipt of a Loan]. Biryukov S.Yu., Kayrgaliev D.V., eds. Aktualnye voprosy sovremennoy yuridicheskoy nauki: sb. st. Mezhdunar. nauch.-prakt. konf. (17 fevr. 2017 g.) [Current Problems of Modern Legal Science: Collected Papers of International Research andPractice Conference(February 17, 2017)]. Almaty,LEM Publ., 2017.

\section{Information about the Authors}

Svyatoslav Yu. Biryukov, Head of Department of Preliminary Investigation, Volgograd Academy of the Ministry of Interior of Russia, Istoricheskaya St., 130, 400089 Volgograd, Russian Federation, bir.slav@yandex.ru, https://orcid.org/0000-0002-7277-1926

Vladimir M. Shinkaruk, Candidate of Sciences (Jurisprudence), Associate Professor of Department of Criminal Procedure and Criminalistics, Volgograd State University, Prosp. Universitetsky, 100, 400062 Volgograd, Russian Federation, shinkaruk@volsu.ru, shinkarukvm@gmail.com, https://orcid.org/0000-0002-1047-4475

\section{Информация об авторах}

Святослав Юрьевич Бирюков, начальник кафедры предварительного расследования, Волгоградская академия МВД России, ул. Историческая, 130, 400089 г. Волгоград, Российская Федерация, bir.slav@yandex.ru, https://orcid.org/0000-0002-7277-1926

Владимир Маркович Шинкарук, кандидат юридических наук, доцент кафедры уголовного процесса и криминалистики, Волгоградский государственный университет, просп. Университетский, 100, 400030 г. Волгоград, Российская Федерация, shinkaruk@volsu.ru, shinkarukvm@gmail.com, https://orcid.org/0000-0002-1047-4475 